\title{
Derecho alimentario en el Perú: propuesta para desformalizar el proceso
}

Nelson Reyes Ríos

\section{Concepto jurídico de alimentos}

Según el diccionario de la Real Academia de la Lengua, ${ }^{1}$ constituyen alimentos cualquier sustancia que puede ser asimilada por el organismo y usada para mantener sus funciones vitales, caso especial de los seres humanos.

Sin embargo, toda persona humana, como sujeto de este derecho esencial, requiere además de subsistir, desarrollarse como tal, para lo cual necesita de otros factores esenciales como: salud, educación, vivienda, recreo, entre otros, y es en razón de ello que en el campo del Derecho se ha elaborado un concepto jurídico con un sentido más amplio, que es recogido por las legislaciones de cada país.

En el caso del Perú, el artículo $472^{\circ}$ del Código Civil, ${ }^{2}$ aplicable en forma genérica para adultos, ha sido modificado para los casos de menores por el Código de los Niños y Adolescentes $^{3}$ (artículo 101\%), con el siguiente texto: «Se considera alimentos lo necesario para el sustento, habitación, vestido, educación, instrucción y capacitación para el trabajo, asistencia médica y recreación del niño o adolescente. También se consi-

1 Diccionario de la lengua española de la Real Academia Española, 1992. Vigésima Primera edición. Editorial Espasa Calpe Sociedad Anónima.

2 Código Civil: Editora Normas Legales Sociedad Anónima. Tercera Edición - abril de 1997. Trujillo - Perú

3 Edwin Sevillano Altuna, Victoria Mendoza Otiniano: Código de los Nirios y Adolescentes. Editora Normas Legales Sociedad Anónima . 1994 - Trujillo Perú. 
dera alimentos los gastos del embarazo de la madre desde la concepción hasta la etapa del post- partom.

Por consiguiente, existe un concepto jurídico de los alimentos, como se comenta en la Enciclopedia Jurídica OMEBA, ${ }^{4}$ indicando que "comprende todo aquello que una persona tiene derecho a percibir de otra por ley, declaración judicial o convenio- para atender a su subsistencia, habitación, vestido, asistencia médica, educación e instrucción”.

Este criterio está sustentado en la Declaración de los Derechos Humanos y en la Convención sobre los Derechos del Niño, normas internacionales que el Perú suscribió, convirtiéndolas en ley interna, como se consagra en el artículo $55^{\circ}$ de la Constitución Política "Los tratados celebrados por el Estado y en vigor forman parte del derecho nacional».

En cuanto a la Declaración de los Derechos Humanos ${ }^{6}$, suscrita y proclamada en París el 10 de diciembre de 1948 por la Asamblea General de las Naciones Unidas en su Resolución $\mathrm{N}^{\circ} 217 \mathrm{~A}$, y aprobada en el Perú por Resolución Legislativa $\mathrm{N}^{\circ} 13282$ del 15 de diciembre de 1959, establece en su artículo $3^{\circ}$ : «todo individuo tiene derecho a la vida, a la libertad y a la seguridad de su persona». El artículo $25^{\circ}$, inciso 1: «Toda persona tiene derecho a un nivel de vida adecuado que le asegure, así como a su familia, la salud y el bienestar, y en especial la alimentación, el vestido, la vivienda, la asistencia médica y los servicios sociales necesarios; tiene asimismo derecho a los seguros en caso de desempleo, enfermedad, invalidez, viudez, vejez y otros casos de pérdida de sus medios de subsistencia por circunstancias independientes a su voluntad.» Inciso $2^{\circ}$ : «La maternidad y la infancia tienen derecho a cuidados y asistencia especiales. Todos los niños, nacidos de matrimonio o fuera de matrimonio, tienen derecho a igual protección social.»

En cuanto a la Declaración sobre los Derechos del $\mathrm{Niño}^{7}$, proclamada por la Asamblea General de las Naciones Unidas el 20 de noviembre de 1989 por Resolución No 1383, suscrita por el Perú el 26 de enero de 1990 y aprobada mediante Resolución Legislativa № 25278 con fecha

4 Enciclopedia Jurídica Omeba: Tomo I, p, 645, Driskill Sociedad Anónima- 1986. Buenos Aires - Argentina.

5 Constitución Política del Perú.- Edición Oficial 1993.

6 Declaración de los Derechos Humanos.- suscrita y proclamada el 10 de diciembre de 1948, por la Asamblea General de las Naciones Unidas.

7 Declaración de los derechos del Niño proclamada por la Asamblea General de las Naciones Unidas el 20 de noviembre de 1989. 
3 de agosto del mismo año, ratificada por el señor Presidente de la República con fecha 14 de agosto de 1990, entra en vigencia en el Perú como ley interna con fecha 2 de setiembre del referido año. Este instrumento internacional contiene disposiciones expresas sobre el derecho de alimentos de los niños, sobre la base de los siguientes principios:

Principio 2: «El niño gozará de una protección especial y dispondrá de oportunidades y servicios, dispensado todo ello por la ley y por otros medios, para que pueda desarrollarse física, mental, moral espiritual y socialmente en forma saludable y normal, así como en condiciones de libertad y dignidad. Al promulgar leyes con este fin, la consideración fundamental que se atenderá, será el interés superior del niño.»

Principio 4: «El niño debe gozar de los beneficios de la Seguridad Social. Tendrá derecho a crecer y desarrollarse en buena salud; con este fin deberán brindarles tanto a él como a su madre, cuidados especiales, incluso atención prenatal y post-natal. El niño tendrá derecho a disfrutar de alimentación, vivienda, recreo y servicios médicos adecuados».

En consecuencia, los alimentos constituyen un factor indispensable para la vida, sin los cuales el individuo perecerá indefectiblemente, y en el caso de que no sean suficientes, se verá limitado en su desarrollo integral, físico mental y psicológico, por cuya razón considero que toda omisión en su cumplimiento es un verdadero atentado contra los Derechos Humanos.

\section{Naturaleza jurídica de los alimentos}

Con el análisis de este tema tratamos de precisar las propiedades, principios o reglas jurídicas aplicables a los alimentos. ¿Cómo considerar a los alimentos en el campo del Derecho? Dentro del campo genérico, se le considera como una obligación, si fuera así, surge la pregunta de rigor ¿serán validas las reglas del derecho de obligaciones, se le puede considerar como una obligación común, especial o mixta? En definitiva, ¿̇e qué naturaleza jurídica está considerada los alimentos? . 
Por lo tanto, habiéndose analizado el concepto jurídico de alimentos, también resulta necesario precisar su naturaleza jurídica. Al respecto, la Enciclopedia Jurídica $\mathrm{Omeba}^{8}$ señala lo siguiente: «Uno de los significados fundamentales que presenta la palabra "naturaleza» en el vocabulario filosófico es el de esencia de un género. Este es definido como una clase, es decir como un conjunto de objetos que poseen, todos ellos y solamente ellos, determinados caracteres comunes. Referido al mundo jurídico, esto significa establecer la equivalencia entre la naturaleza del Derecho y su esencia. Dicho de otro modo, la naturaleza del Derecho es el conjunto de propiedades que permiten definir, entre los objetos, un sector que presenta características comunes (la juricidad), y al cual llamamos lo jurídicom.

El Instituto Interamericano del Niño abordó este tema en la Cuarta Conferencia Especializada Interamericana sobre Derecho Internacional Privado. El Dr. Didier Opertti Badan, profesor de Derecho Internacional Privado de Montevideo, se encargó de preparar la exposición de motivos del proyecto de Convención Interamericana sobre conflictos de leyes en materia de alimentos para menores (Montevideo, Uruguay, 1988). En aquella oportunidad se hizo referencia que: «reconociendo su calidad de instituto de protección del menor -sobre el que no existe duda- no se adopta una posición doctrinaria categórica en orden a la definición de su naturalezan. Muchos autores consideran al respecto lo siguiente :

- Que se trata de una obligación legal, ex delito, por lo que en el ámbito de los tratados de Montevideo se les colocaría dentro del alcance de las también llamadas obligaciones extracontractuales. A nuestro juicio, señala el profesor Opertti, «la obligación alimentaria contiene siempre como base una cierta relación jurídica del derecho de familia - puede variar su carácter- con lo cual no podría identificarse con la responsabilidad delictual y cuasi-delictual; en ciertos casos el nacimiento es el producto de un acto delictivo (forzamiento o violación, engaño etc.) pero ello no sustrae el tema, en estos aspectos, del campo del derecho de familia".

- Que es un efecto de relaciones jurídicas del derecho de familia (en caso de menores, efecto de la filiación, o de las relaciones de los padres con

8 Enciclopedia Jurídica Omeba: Tomo XX, p, 74, Driskill Sociedad Anónima- 1986. Buenos Aires - Argentina. 
los hijos, o de la protección de los incapaces, o de la adopción -según cita del Dr. Opertti; Alfonsín Quintin en su obra sobre Sistema del Derecho Civil Internacional, vol.1, ed. Montevideo, 1961, expone estas distintas posturas.

- Eduardo Vaz Ferreyra, también citado por Opertti, en su obra sobre obligación alimentaria en Argentina, se pronuncia en favor de la autonomía científica de ésta. Por lo tanto, se trata de un derecho humano o autónomo -en sentido amplio- y como tal de una categoría jurídica específica.

- Que se trata de una obligación dineraria más, u ordinaria. En aplicación de esta posición, se llegó a sostener que en los casos de incumplimiento no procedería la sanción de la pena privativa de la libertad. Vaz Ferreyra, en su obra referida, argumenta en contra de tal calificación, señalando que el derecho de alimentos no puede ser objeto de venta, cesión, gravamen o garantía y su carácter irrenunciable lo sustrae del comercio de los hombres para convertirlo en un derecho tutelado aún contra la voluntad del titular.

De todo lo expuesto, se considera que el derecho alimentario es un derecho que corresponde a toda la humanidad, como un derecho natural, originado por las necesidades de la propia naturaleza humana, por lo tanto puede ser considerado como un derecho humano de primera categoría, por su repercusión en todos los seres humanos, cuya omisión o limitación, como se dijo, no solo los llevaría a su aniquilamiento, si no además a la disminución en su formación. Se trata de un derecho de categoría especial, que forma parte, como todo el contenido del derecho de familia, del Derecho Social. ${ }^{9}$

\section{Obligados a la prestación de alimentos : casos generales y especia- les}

Como se mencionó, la obligación alimentaria se origina dentro de las relaciones de orden familiar, por lo tanto, nacen recíprocas obligaciones y derechos. En nuestra legislación se ha establecido como obligados recí- 
procos a los cónyuges, los descendientes, los ascendientes y los hermanos. Así está considerado en el artículo $474^{\circ}$ del Código Civil: ${ }^{10}$ "Se deben alimentos recíprocamente: 1 . Los cónyuges. 2 . Los ascendientes y descendientes. 3. Los hermanos."

Con respecto a esta regla debemos hacer algunas precisiones. Para los casos en que resulten varios obligados a la vez, como puede suceder entre los cónyuges con los descendientes o ascendientes, y en otros casos cuando existen varios hermanos, la ley establece una prelación como se señala en los artículos $475^{\circ}$ y $476^{\circ}$ del C.C. (Art. $475^{\circ}$ : «los alimentos, cuando sean dos o más los obligados a darlos, se prestan en el orden siguiente : 1. Por el cónyuge. 2. Por los descendientes. 3. Por los ascendientes y 4. Por los hermanos». Art. $476^{\circ}$ "entre los descendientes y los ascendientes se regula la gradación por el orden en que son llamados a la sucesión legal del alimentista». Por ejemplo, cuando hay hijos y nietos, heredan en primer lugar los hijos. En el caso de los hermanos, se precisa: Art. $477^{\circ}$ "cuando sean dos o más los obligados a dar los alimentos, se divide entre todos el pago de la pensión en cantidad proporcional a sus respectivas posibilidades. Sin embargo, en caso de urgente necesidad y por circunstancias especiales el Juez puede obligar a uno solo a que los preste, sin perjuicio de su derecho a repetir de los demás la parte que les corresponda"

\subsection{Obligación de asistencia recíproca entre los cónyuges}

El fundamento de esta obligación se origina en el deber fundamental de asistencia que tienen los cónyuges por efecto del matrimonio. Así, se establece de manera genérica en el artículo $288^{\circ}$ del C. C. que «los cónyuges se deben recíprocamente fidelidad y asistencia». Lógicamente el presupuesto es que el vínculo matrimonial se encuentre vigente.

Sin embargo, aun vigente el vínculo matrimonial cesa la prestación de alimentos entre cónyuges en caso de abandono. Así se establece en el segundo parágrafo del artículo $291^{\circ}$ del C. C. cuando señala "Cesa la obligación de uno de los cónyuges de alimentar al otro cuando éste abandona la casa conyugal sin causa justa y rehusa volver a ella. En este

10 Código Civil: Editora Normas Legales Sociedad Anónima. Tercera Edición - abril de 1997. Trujillo - Perú 
caso el Juez puede según las circunstancias, ordenar el embargo parcial de las rentas del abandonante en beneficio del cónyuge inocente y de los hijos». La explicación es lógica, sustentado en el deber de hacer vida común de los cónyuges, como se establece en el Art. $289^{\circ}$ del C. C. que señala: «Es deber de ambos cónyuges hacer vida común en el domicilio conyugal. El Juez puede suspender este deber cuando su cumplimiento ponga en grave peligro la vida, la salud o el honor de cualquiera de los cónyuges o la actividad económica de la que depende el sostenimiento de la familia».

Otra forma de suspender la vida común de los cónyuges es mediante el trámite de la separación de cuerpos, como lo señala de manera expresa el Art. $332^{\circ}$ del C. C.: "la separación suspende los deberes relativos al lecho y habitación y pone fin al régimen patrimonial de sociedad de gananciales, dejando subsistente el vínculo matrimonial". En este caso, será en dicho proceso en el que habrá de fijarse la pensión de los cónyuges, de acuerdo al Art. $342^{\circ}$ del C. C., que dice: «El Juez señala en la sentencia la pensión alimenticia que los padres o uno de ellos debe abonar a los hijos, así como la que el marido debe pagar a la mujer o viceversa."

También debe indicarse que en caso de insolvencia del cónyuge, la obligación pasa en el orden señalado a otros parientes, según lo dispuesto en el Art. 478 del C. C. «si teniéndose en cuenta las demás obligaciones del cónyuge deudor de los alimentos, no se halla en condiciones de prestarlos sin poner en peligro su propia existencia, según su situación, están obligados los parientes antes que el cónyuge».

\subsection{Casos de excepción sobre la obligación alimentaria entre cónyuges}

\subsubsection{Situación de los ex-cónyuges}

Si bien no existe observación sobre la obligación alimentaria recíproca entre los cónyuges estando vigente el vínculo matrimonial, sin embargo, por excepción, y con un carácter esencialmente humanitario y solidario, se permite que subsista dicha obligación en los casos de ex-cónyuges. Para este caso, según nuestro sistema, se considera como sanción, por lo que siempre será necesario que se determine la culpa del obligado. Así, se establece en el Art. $350^{\circ}$ del C. C.: «Por el divorcio cesa la obligación alimenticia entre marido y mujer. Si se declara el divorcio por culpa de uno de los cónyuges y el otro careciere de bienes propios o de gananciales 
suficientes o estuviere imposibilitado de trabajar o de subvenir a sus necesidades por otro medio, el juez le asignará una pensión alimenticia no mayor de la tercera parte de la renta de aquél. El ex-cónyuge puede, por causas graves, pedir la capitalización de la pensión alimenticia y la entrega del capital correspondiente. El indigente debe ser socorrido por su excónyuge aunque hubiese dado motivos para el divorcio. Las obligaciones a que se refiere este artículo cesan automáticamente si el alimentista contrae nuevas nupcias. Cuando desaparece el estado de necesidad, el obligado puede demandar la exoneración y, en su caso, el reembolso".

Del texto del artículo citado se puede extraer dos ideas muy claras sobre los alimentos. La primera es el criterio de capitalización de la pensión alimenticia, para lo cual debe haber un pensión establecida, en cuyo caso se debe acreditar las causas graves como, por ejemplo, una enfermedad o una intervención quirúrgica inminente.

El otro aspecto que merece un esclarecimiento, es el caso de reembolso cuando desaparece el estado de necesidad, al que se refiere la última parte del mencionado artículo. Claro está que procederá tal reembolso cuando haya mediado mala fe en el petitorio, por cuanto los actos de buena fe producen consecuencias jurídicas válidas, no así los de mala fe, ni el ejercicio abusivo del derecho, como se establece en el Art. II del T. P. del C. C. que señala «la ley no ampara el ejercicio ni la omisión abusivos de un derecho. Al demandar indemnización u otra pretensión, el interesado puede solicitar las medidas cautelares apropiadas para evitar o suprimir provisionalmente el abuso».

\subsubsection{Situación de los concubinos}

Nuestra legislación admite la regulación del concubinato de manera restringida sólo para ciertos efectos, como son los de carácter patrimonial y para el caso de la filiación. Sin embargo, también establece el derecho de alimentos en una forma muy especial, solo bajo ciertas condiciones, como la falta de impedimentos matrimoniales, el tiempo establecido de convivencia, así como la culpa de la ruptura de la unión, en cuyo caso el culpable queda obligado a favor del inocente o abandonado con una pensión de alimentos o, en su defecto, con una alternativa, con una suma alzada por concepto de indemnización. Así se estipula en el Art. $326^{\circ} \mathrm{del}$ C. C.: «La unión de hecho, voluntariamente realizada y mantenida por un varón y una mujer, libres de impedimento matrimonial, para alcanzar 
finalidades y cumplir deberes semejantes a los del matrimonio, origina una sociedad de bienes que se sujeta al régimen de sociedad de gananciales, en cuanto le fuere aplicable, siempre que dicha unión haya durado por lo menos dos años continuos. La posesión constante de estado a partir de fecha aproximada puede probarse con cualquiera de los medios admitidos por la ley procesal, siempre que exista un principio de prueba escrita. La unión de hecho termina por muerte, ausencia, mutuo acuerdo o decisión unilateral. En este último caso, el juez puede conceder, a elección del abandonado, una cantidad de dinero por concepto de indemnización o una pensión de alimentos, además de los derechos que le correspondan de conformidad con el régimen de sociedad de gananciales. Tratándose de la unión de hecho que no reúna las condiciones señaladas en este artículo, el interesado tiene expedita, en su caso, la acción de enriquecimiento indebido".

\subsubsection{Situación de las madres solteras}

Las madres que tienen hijos extramatrimoniales, reconocidos por los padres o declarados judicialmente, que no estén bajo el amparo del concubinato, también tienen un derecho de alimentos, limitado a un tiempo determinado de 60 días anteriores y 60 días posteriores al parto. Este derecho se justifica toda vez que en dichas etapas la madre se encuentra generalmente imposibilitada de trabajar y requiere de un sustento. Al respecto, consideramos que el límite de tiempo es corto y que debe ser ampliado según las circunstancias y la necesidad de atención del hijo. En todo caso, el Art. $414^{\circ}$ del C. C. señala: «En los casos del artículo 402\%, así como cuando el padre ha reconocido al hijo, la madre tiene derecho a alimentos durante los sesenta días anteriores y los sesenta posteriores al parto, así como al pago de los gastos ocasionados por éste y por el embarazo. También tiene derecho a ser indemnizada por el daño moral en los casos de abuso de autoridad o de promesa de matrimonio, si esta última consta de modo indubitable, de cohabitación delictuosa o de minoridad al tiempo de la concepción. Estas acciones son personales, deben ser interpuestas antes del nacimiento del hijo o dentro del año siguiente; se dirigen contra el padre o sus herederos o pueden ejercitarse ante el juez del domicilio del demandado o del demandante». 


\subsection{Obligacion alimentaria de los ascendientes}

Como se indicó anteriormente, frente a la obligación de los ascendientes nace el derecho de los descendientes para percibir la prestación de alimentos, según la prelación del orden sucesoral. Es decir, que los más próximos excluyen a los mas lejanos. Y, de esta manera, los hijos tienen prioridad sobre los demás descendientes. Esta obligación nace como consecuencia o efecto del vínculo de filiación establecido jurídicamente, que puede ser matrimonial, extramatrimonial o de adopción. Este vínculo o lazo, a su vez, origina deberes y derechos de los padres, dando lugar a lo que se conoce como la patria potestad, que se ejerce hasta que los hijos cumplan la edad de 18 años. Así, se establece en el Art. $418^{\circ}$ del C. C.: «Por la patria potestad los padres tienen el deber y el derecho de cuidar de la persona y bienes de sus hijos menores". Asimismo, el Art. $423^{\circ} \mathrm{C}$. C. dice: «son deberes y derechos de los padres que ejercen la patria potestad: [...] inc. 1) proveer al sostenimiento y educación de los hijos».

Por otro lado, el Art. $82^{\circ}$ del C. de los N. y A. establece: «Son deberes y derechos de los padres que ejercen la patria potestad respecto de los niños y adolescentes que son sus hijos los siguientes: [...] b) proveer su sostenimiento y educación.» La obligación concluye cuando termina la patria potestad o se extingue, como se establece en el Art. $461^{\circ}$ del C. C.: «La patria potestad se acaba [...] 3) por cumplir el hijo 18 años de edad".

De acuerdo al Art. $84^{\circ}$ del Código de los Niños y Adolescentes «la patria potestad se extingue [...] b) porque el adolescente adquiere la mayoría de edad».

\subsubsection{Obligación alimentaria de los demás ascendientes}

Es necesario considerar un primer caso, en el que la obligación alimentaria no pasa a los demás ascendientes. Tal es el caso de los llamados hijos alimentistas, es decir, en el que los acreedores alimentarios no tienen establecido jurídicamente el vínculo de filiación. El Art. $480^{\circ}$ del C. C. dice: «la obligación de alimentarse que tiene un padre y su hijo extramatrimonial no reconocido ni declarado, conforme a lo dispuesto en el Art. $415^{\circ}$, no se extiende a los descendientes y ascendientes de la línea paterna». En la redacción de este dispositivo se presenta la interrogante ¿los llamados padres que para la ley no lo son, 
pueden reclamar alimentos del hijo que tampoco lo es? Solo se ha establecido para aquellos que hayan mantenido relaciones sexuales con la madre durante la época de la concepción.

En cambio, es diferente la otra situación que puede presentarse, es decir, la de los padres que por causa de pobreza no pueden sufragar los alimentos de sus hijos. Ante tal circunstancia, es justo y lógico que los demás ascendientes, los abuelos, asuman dicha obligación de acuerdo a sus posibilidades. El Art. $479^{\circ}$ del C.C. señala: «Entre los ascendientes y los descendientes, la obligación de darse alimentos pasa por causa de pobreza del que debe prestarlos al obligado que le sigue».

El Código de los Niños y Adolescentes establece de manera especial un orden para cumplir con la prestación alimentaria en ausencia de los padres. Según su Art. $102^{\circ}$ «Es obligación de los padres prestar alimentos a sus hijos. Por ausencia de éstos, prestarán alimentos en el orden siguiente: 1 . los hermanos mayores de edad; 2. los abuelos; 3. los parientes colaterales hasta el tercer grado; 4 . otros responsables del niño o adolescente». En este último caso se encuentran los tutores, guardadores y otros. Como se establece en el Art. 526 $\mathrm{del} \mathrm{C.} \mathrm{C.:} \mathrm{«El} \mathrm{tutor} \mathrm{debe} \mathrm{alimentar} \mathrm{y}$ educar al menor de acuerdo a la condición de éste y proteger y defender su persona». Asimismo, el Art. $108^{\circ}$ del Código de los Niños y Adolescentes «Son deberes y derechos del tutor los mismos que prescribe el presente Código y la legislación vigente respecto de los padres del niño y adolescente». Por otro lado, en el Art. $111^{\circ} \mathrm{del}$ mismo Código se dice: «El guardador tiene los mismos deberes y derechos que los estipulados en el presente Código y la legislación vigente para los padres».

\subsubsection{Situación de los hijos mayores de edad}

En situación excepcional, subsiste la obligación alimentaria para los hijos mayores de edad, cuando no se encuentren en posibilidades de sufragar su sostenimiento o cuando se encuentren cursando estudios. Aun cuando la ley señala que deben considerarse los estudios superiores y con éxito, consideramos que debe tenerse en cuenta sólo la situación de estudios en general, como se ha establecido en varias resoluciones jurisprudenciales. El Art. $424^{\circ}$ del C. C. señala: "subsiste la obligación de proveer al sostenimiento de los hijos e hijas mayores de 18 años que estén siguiendo con éxito una profesión u oficio, y de las hijas solteras que no se encuentren en aptitud de atender su sulisisten- 
cia». Asimismo, el Art. $473^{\circ}$ establece lo siguiente: «El mayor de 18 años sólo tiene derecho a alimentos cuando no se encuentra en aptitud de atender a su subsistencia. Si la causa que lo ha reducido a ese estado fuese su propia inmoralidad, sólo podrá exigir lo estrictamente necesario para subsistir. No se aplica lo dispuesto en el párrafo anterior cuando el alimentista es ascendiente del obligado a prestar los alimentos".

\subsubsection{Pérdida del derecho de alimentos del alimentista indigno}

Por razones de consideraciones ético moral, el alimentista declarado indigno o desheredado por las causales que señala la ley, lógicamente pierde el derecho de alimentos de manera general. El Art. $485^{\circ}$ del C. C. señala: «el alimentista que sea indigno de suceder o que pueda ser desheredado por el deudor de los alimentos, no puede exigir sino lo estrictamente necesario para subsistir".

\subsection{Obligación alimentaria de los descendientes}

De manera recíproca existe este derecho entre los descendientes y ascendientes como se indicó anteriormente. El sustento para establecer la obligación alimentaria de los descendientes a favor de los ascendientes, es idéntico al señalado para los descendientes, los que se basan también en la relación de la filiación y la paternidad o maternidad. Sin embargo, es necesario considerar algunos casos especiales.

\subsubsection{Pérdida del derecho alimentario de los padres}

Por excepción, quienes son jurídicamente padres, pierden el derecho de alimentos y sucesorales, cuando practican el reconocimiento de un hijo extramatrimonial mayor de edad sin su consentimiento o no mediando posesión constante de estado de hijo. En este caso es válido el reconocimiento, sin embargo, por razones de orden ético moral, social y jurídico, para que el reconocimiento de un hijo mayor de edad, surta efecto plenos, por lo menos debe existir su consentimiento, y evitar que el reconocimiento se realice solo para sacar ciertas ventajas económicas en algún caso. El Art. $398^{\circ}$ del C. C. afirma: «el reconocimiento de un hijo mayor de edad no confiere al que lo hace dere- 
chos sucesorios ni derecho a alimentos, sino en caso que el hijo tenga respecto de él la posesión constante de estado o consienta en el reconocimiento".

Cuando la filiación de los hijos extramatrimoniales ha sido declarada judicialmente, el padre pierde el derecho alimentario del hijo, situación que es justificada por la negativa para el reconocimiento. El Art. $412^{\circ}$ del C. C. dice: «la sentencia que declara la paternidad o la maternidad extramatrimonial produce los mismos efectos que el reconocimiento. En ningún caso se confiere al padre o a la madre derecho alimentario ni sucesorio".

\subsubsection{Obligados o acreedores alimentarios de hijos no reconocidos}

Este caso se conoce con el nombre de hijos alimentistas. Pues se trata de los hijos reconocidos tan solo por la madre no así por los padres, quienes jurídicamente sólo están obligados a prestar alimentos. Esta figura se ha establecido en el C. C. de 1936, ${ }^{11}$ así como en el actual C. C. de 1984, originándose por el sistema restrictivo, sobre el establecimiento de la filiación extramatrimonial. Como una forma de compensar dicho sistema, se ha establecido que están obligados a la prestación de alimentos los que hayan mantenido relaciones sexuales con la madre durante la época de la concepción. Así se estipula en el Art. $415^{\circ}$ del C .C.: «Fuera de los casos del Art. 402, el hijo extramatrimonial sólo puede reclamar del que ha tenido relaciones sexuales con la madre durante la época de la concepción una pensión alimenticia hasta la edad de 18 años. La pensión continúa vigente si el hijo, llegado a la mayoría de edad, no puede proveer a su subsistencia por incapacidad física o mentaly.

\subsection{Derecho y obligación alimentaria entre los hermanos}

No debe perderse la idea del principio de prelación, tanto para cumplir con la obligación así como para reclamar el derecho de los alimentos, que para este caso se rige por el orden sucesoral, como se indicó en el análisis de los arts. $475^{\circ}$ y $476^{\circ}$ del C. C. En estos casos, 
se pueden presentar la prestación de alimentos entre hermanos, en tal situación la obligación debe prorratearse, de acuerdo a la capacidad económica y necesidades de éstos, conforme a las reglas que establecen los arts. $481^{\circ}$ y $482^{\circ}$ del C. C. Así, se estipula en el Art. $477^{\circ} \mathrm{del}$ mismo C. C.: "Cuando sean dos o más obligados a dar los alimentos, se divide entre todos el pago de la pensión en cantidad proporcional a sus respectivas posibilidades. Sin embargo, en caso de urgente necesidad y por circunstancias especiales, el juez puede obligar a uno solo a que los preste, sin perjuicio de su derecho a repetir de los demás la parte que les corresponda».

\section{Forma y modo de hacer efectivo el cumplimiento de la obligación alimentaria}

\subsection{Formas:}

En lo que respecta a la forma de hacer efectivo el cumplimiento de la obligación alimentaria, existe en la práctica serias dificultades, pese a que nuestra legislación positiva señala que la pensión puede fijarse en :A) Efectivo, mediante una pensión. la misma que puede ser fijada en suma determinada o en porcentaje, y B) En forma diferente al pago de una pensión (entrega de especies), debiendo tenerse en cuenta las posibilidades del obligado.

Con estos criterios, no debería existir en la práctica dificultades para fijar la pensión de los alimentos, ya que para tomar en cuenta las posibilidades del obligado, se debe partir del principio de que éste debe asumir dicha obligación a priori, puesto que la responsabilidad de los progenitores es compartida. Asimismo, debe tenerse presente el principio de presunción juris tantum, que el obligado sí puede asumir tal obligación, además de otros datos adicionales como su condición personal (profesional), o la referencia que aporta la parte reclamante de la parte reclamada sobre alguna actividad que este realizando (artista, comerciante, u ocupado en cualquier otro oficio). Por último, no resulta necesario investigar rigurosamente los ingresos del que debe prestar los alimentos. Con los elementos que se tiene y tomando en cuenta las necesidades reales y elementales del alimentista (edad, salud, grado de instrucción etc.) debe fijarse la pensión. 
Estas consideraciones están señaladas en nuestro ordenamiento sustantivo, lo que falta es un poco más de criterio para asumir en fijar la pensión que corresponda, invirtiéndose la carga de la prueba, para que el obligado acredite su imposibilidad o grado de posibilidad. Así, el Art. $481^{\circ}$ del C. C. indica: «Los alimentos se regulan por el juez en proporción a las necesidades de quien los pide y a las posibilidades del que debe darlos, atendiendo además a las circunstancias personales de ambos, especialmente a las obligaciones a que se halle sujeto el deudor. No es necesario investigar rigurosamente el monto de los ingresos del que debe prestar los alimentos». Por otro lado, el Art. $482^{\circ}$ del mismo C.C. señala: «La pensión alimenticia se incrementa o reduce según el aumento o la disminución que experimenten las necesidades del alimentista y las posibilidades del que debe prestarla. Cuando el monto de la pensión se hubiese fijado en un porcentaje de las remuneraciones del obligado, no es necesario nuevo juicio para reajustarla. Dicho reajuste se produce automáticamente según las variaciones de dichas remuneraciones».

Con respecto a la interpretación de este dispositivo, cabe mencionar algunas precisiones. Primero, se debe orientar su interpretación bajo el principio del llamado interés superior del niño, todo lo más conveniente o favorable al niño o menor, que establece la Convención sobre los Derechos del Niño. Segundo, se ha pretendido sostener que no procede otro juicio cuando la pensión ha sido fijada en porcentaje, por cuanto el reajuste es regulado automáticamente. Esta posición resultaría favorable, siempre y cuando el porcentaje fijado halla estado de acuerdo a las necesidades y posibilidades del alimentista y obligado; en consecuencia, el reajuste se regularía automáticamente. Sin embargo, en el caso de que existan nuevas necesidades, el porcentaje podría resulta ínfimo. No habría, por tanto, dificultad para que se inicie un proceso de aumento de alimentos y así obtener un mayor porcentaje al señalado. Por ejemplo, si originalmente se fijó en el $40 \%$, no existe inconveniente para que posteriormente se fije en 45 o $50 \%$, provocando así como se procede para los aumentos de la pensión fijada en una suma alzada.

En cuanto a la forma diferente de la pensión, es permitido que ésta se realice en especies -por ejemplo,: en víveres, medicinas, estudios, etc.-, teniendo en cuenta que debe existir el acuerdo de los obligados, y que se proporcione según la mayor necesidad del alimentista. 


\subsection{Modos de hacer efectivo la pensión alimentaria}

A nuestro criterio, este es el aspecto central del problema sobre el cumplimiento de la obligación alimentaria en el Perú. En el ámbito procesal son novísimas las disposiciones que contiene el Código de los Niños y Adolescentes en el que se establece un proceso único y breve. El Art. $106^{\circ}$ señala: «El proceso de alimentos se tramitará conforme a las disposiciones contenidas en el proceso único del presente Código". Más aún, en el nuevo Código Procesal Civil se le ha incluido dentro de los denominados procesos sumarísimos, por la brevedad del trámite. No obstante ello, en una investigación de campo realizada en los Juzgados de Familia, sobre la tramitación y ejecución de los procesos de alimentos, se ha podido verificar que:

1. La mayoría de las acciones concluyen mediante conciliación en cuanto a la fijación de la pensión. Sin embargo, el $90 \%$ de dichos procesos se encuentran sin poder ejecutar dicho compromiso. Para estos casos, se dice que con la aplicación de la ley de conciliación se van a considerar como títulos ejecutivos los mismos. Es decir, un nuevo proceso.

2. En muchos otros casos, después de admitida la demanda no puede notificarse al obligado por deficiencia del domicilio, lo que origina la paralización del proceso.

3. En un trámite normal un proceso de alimentos puede concluirse (con sentencia o conciliación) en el plazo de 5 ó 8 meses, empero la demora se ocasiona en la ejecución de la obligación

4. De los procesos que se encuentran con sentencia, un promedio del $80 \%$ no se pueden ejecutar por insolvencia del obligado.

5. Se ha comprobado que se demora en averiguar los ingresos del obligado, sea por que no tiene trabajo dependiente o en su defecto los centros de trabajo del obligado no cumplen con evacuar el informe solicitado. En otros casos los distorsionan, incurriendo con ello en actos delictivos.

6. Un $90 \%$ de los que reclaman alimentos muestran su disconformidad con la forma en que se lleva el proceso. No existe efectividad, los justiciables no entienden las formas que tienen que cumplir para hacer efectivo de inmediato su reclamo. 
7. La mayoría de los obligados sostienen que en la práctica están cumpliendo con su obligación, pero no pueden acreditarlo (viven en el mismo domicilio, etc.).

8. El $60 \%$ de las acciones sobre tenencia de los menores son para contrarrestar una demanda de alimentos.

9. Gran parte de los obligados alegan estar desempleado, no tener trabajo estable y tener otras obligaciones.

Si bien es cierto que las normas procesales para reclamar la pensión de alimentos es breve, no se ha tomado en cuenta que la ejecución de dicha obligación se rige bajo las normas establecidas en el Código Procesal Civil, como si se tratara de cualquier obligación, teniendo que recurrir a las medidas cautelares como es el embargo, de los bienes muebles o inmuebles del obligado -si los tuviera- y después proceder al remate en caso necesario. Esto implica que los modos para ejecutar la obligación alimentaria deben hacerse mas viables, tomando en cuenta el interés superior del niño y adolescente.

Como ilustración de la dificultad existente, se ha preparado un informe respecto al proceso de alimento:

Conforme a lo antes expuesto, podemos afirmar que el grave problema por el que atraviesan nuestros niños y adolescentes, es el incumplimiento de las obligaciones alimenticias de sus progenitores (padre), por tal motivo en la actualidad tanto en las dependencias de la Defensoría del Niño y Adolescente (DEMUNAS), así como en los juzgados especializados de Familia del Distrito Judicial de Lima, se observa que la mayor parte de denuncias son por alimentos.

Entre enero y noviembre de 1999 , se ha registrado que la mayor cantidad de demandas ingresadas se refieren a pensiones alimenticias. 


\section{Cuadro 1}

Enero - noviembre 1999

Materias

\begin{tabular}{|l|c|c|c|c|}
\hline MESES & ALIMENTOS & AUM. ALIMEN & APEL. J. PAZ & OTROS \\
\hline Enero & 154 & 15 & 93 & 653 \\
\hline Febrero & 615 & 134 & 10 & 468 \\
\hline Marzo & 2575 & 400 & 37 & 470 \\
\hline Abril & 457 & 89 & 13 & 361 \\
\hline Mayo & 380 & 52 & 15 & 360 \\
\hline Junio & 324 & 46 & 5 & 351 \\
\hline Julio & 297 & 38 & 3 & 290 \\
\hline Agosto & 350 & 51 & 3 & 731 \\
\hline Setiembre & 405 & 47 & 3 & 692 \\
\hline Octubre & 334 & 29 & 7 & 697 \\
\hline Noviembre & 261 & 23 & 10 & 743 \\
\hline
\end{tabular}

Del cuadro 1 se puede desprender que de enero a noviembre de 1999, ingresaron 13,091 demandas (alimentos, aumento de alimentos apelaciones de procesos de alimentos de juzgado de paz letrado, impugnación de la partida de nacimiento y otros relacionados con el aspecto familiar), de las cuales 6,152 son demanda de alimentos; 924 demandas de aumento de alimentos; 199 procesos de alimentos elevados en apelación de la sentencia, lo que da un total de 7275 procesos de alimentos.

\section{Cuadro 2}

Monto global de ingresos de demandas en los juzgados de familia

\begin{tabular}{|lrc|}
\hline \multicolumn{1}{|c}{ Materias } & Monto Anual & Porcentaje \\
\hline Alimentos & 6,152 & $46.99 \%$ \\
Aumento de Alimen. & 924 & $7.05 \%$ \\
Apel. Juzg. Paz & 199 & $1.54 \%$ \\
Otros & 5,816 & $44.42 \%$ \\
Total & 13,091 & \\
\hline
\end{tabular}


Propuesta mundial para brindar mayor atención a la niñez.

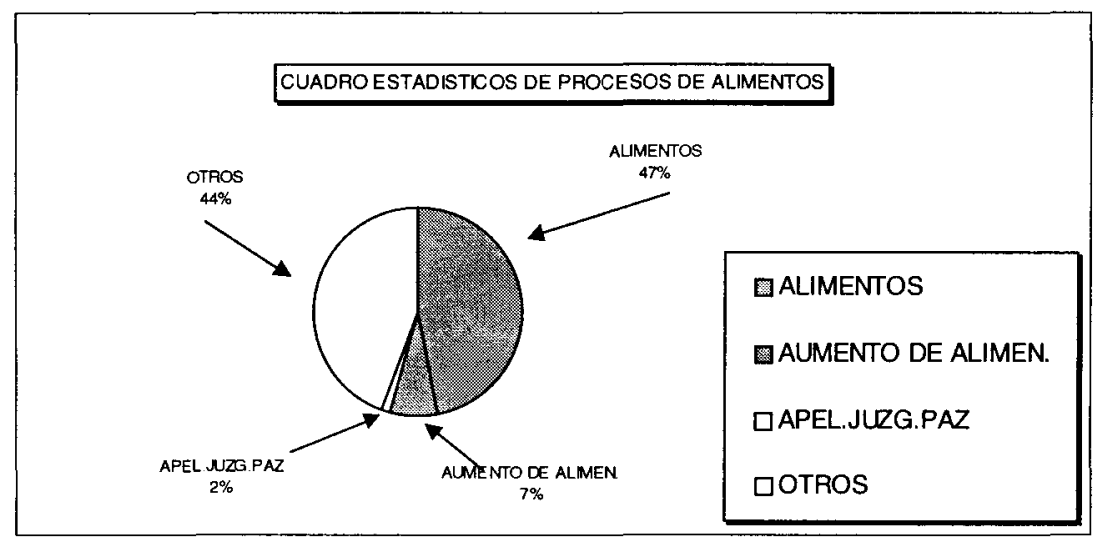

Cumbre para la infancia de 1990. Propuestas para el 2000

En 1991, James P. Grant, director ejecutivo del Fondo de las Naciones Unidas para la Infancia (UNICEF), en una publicación ${ }^{12}$ titulada El estado mundial de la infancia 1991, dio a conocer la situación de la infancia en la década de los 90 , sobre la base de la cumbre mundial a favor de la infancia de 1990, anexado a la declaración mundial sobre la supervivencia, la protección y el desarrollo del niño, así como de un plan de acción para la aplicación de dicha declaración.

$\mathrm{Al}$ respecto, señaló que «El domingo 30 de setiembre de 1990 se hizo una gran promesa a la infancia de los años noventa. Setenta y un presidentes y primeros ministros se reunieron en dicha fecha en la primera Cumbre Mundial en favor de la Infancia, la mas amplia asamblea de jefes de Estado y de gobierno de toda la historia. El resultado final de la Cumbre constituye un compromiso sin precedentes pués se derivo en la decisión de poner fin a los actuales niveles de mortalidad y desnutrición infantiles antes del año 2000 y de velar por la protección del desarrollo físico y mental normal de todos los niños del mundo. Esta meta global se desglosó en más de veinte objetivos específicos recogidos en el Plan de Acción aprobado en la Cumbre. Todos los gobiernos revisarán sus planes y presupuestos y elaborarán programas nacionales de acción antes de finales de 1991».

12 James P. Grant Estado mundial de la infancia 1991.. Fondo de las Naciones Unidas para la Infancia 
Es así que los fines globales 1990-2000, elaborados como objetivos para el año 2000 , se hicieron propuestas reales con toda precisión, hallándose entre las principales:

- Reducción de un tercio de las tasas de mortalidad de los menores de cinco años (o una reducción hasta niveles inferiores al 70 por 1000 nacidos vivos, si ello representa una mayor reducción).

- Reducción a la mitad de las tasas de mortalidad materna.

- Una reducción de la desnutrición moderada y grave de los menores de cinco años en todo el mundo.

- Agua potable y saneamiento ambiental para todas las familias.

- Educación básica para todos los niños y terminación de la enseñanza primaria por al menos el $80 \%$ de todos los niños y niñas comprendidos entre los seis y once años.

- Reducción a la mitad de la tasa de analfabetismo adulto e igualdad de oportunidades educativas para hombres y mujeres.

- Protección de los numerosos millones de niños en circunstancias especialmente difíciles y aceptación y observancia en todos los países de la Convención sobre los Derechos del Niño, recientemente adoptada. En particular, los años noventa deberían ser testigos de una rápida aceptación de que los niños merecen una especial protección contra los efectos directos e indirectos de los conflictos bélicos.

En cuanto al plan de acción para la aplicación de la Declaración Mundial, especialmente en el decenio de 1990, se consideran como medidas específicas relacionadas con la supervivencia la protección y el desarrollo del niño, los siguientes:

1. Convención sobre los Derechos del Niño,

2. salud infantil,

3. alimentación y nutrición,

4. función de la mujer, salud materna y planificación de la familia,

5. función de la familia,

6. educación básica y alfabetización,

7. niños en circunstancias especialmente difíciles,

8. protección de los niños en situaciones de conflicto armado,

9. Los niños y el medio ambiente, 
10. Mitigación de la pobreza y reactivación del crecimiento económico.

\section{Análisis del plan de acción a nivel nacional}

En el Perú encontramos avances considerables sobre algunos aspectos de protección a la niñez. En todo caso, la interrogante es jestamos en el nivel deseado? Considero que no. Sin embargo, en cuanto al primer compromiso del plan con respecto a la Convención sobre los Derechos del Niño, se ha cumplido al haberse ratificado sin ninguna observación. Sin embargo, tenemos un gran margen de preocupación con respecto al derecho de los alimentos, conforme se aprecia en las estadísticas elaboradas por una dependencia de la Defensoría de la Niñez y Adolescencia (Demunas), en el que se observa que el incumplimiento de mantener a los hijos es generalizada. Es así que entre 1995 y abril de 1999, las Demunas de Lima y Callao atendieron 34,842 casos ( $38 \%$ del total) vinculados a la pensión alimenticia, por lo que podemos afirmar que esta obligación es la causa principal de denuncias (Diario El Comercio, 19 de noviembre de 1999).

\subsection{Hipótesis de trabajo}

Frente a esta realidad, ad portas de un nuevo milenio, con una globalización galopante, en plena vigencia de la Convención de los Derechos del Niño suscrito por el Perú, y por lo tanto ley interna de rango constitucional, ¿qué soluciones de corto, mediano o largo plazo se puede proponer, convenir y aplicar? Realmente la tarea sigue siendo ardua, pero no imposible, aunque pues se requiere la participación de todos los sectores. Por lo que tomamos sólo algunas de las posibilidades como hipótesis de trabajo:

1. Acciones tendientes para asumir responsabilidades por convicción.

2. Programas educativos en todo nivel. Sector Educación.

3. Programas sobre generación de empleos. Sector Trabajo.

4. Programas de salud y planificación familiar. Sector Salud.

5. Programas tuitivos de protección a la familia. Promudeh.

6. Cambio radical de normas y procedimientos sobre procesos de alimento Sector Justicia. 
6.- Difusión e implementación de la autonomía del Derecho Familiar y de la niñez (menores), en el ámbito de su estudio, como derecho Social,. En el ámbito legislativo, con un código de familia sustantivo y procesal, totalmente desformalizado a cada realidad social, geográfica, económica etc. En el ámbito jurisdiccional, especialización y cambio de paradigmas de los jueces de familia.

7. Intensificar los programas de mediación y conciliación en materia familiar, sobre actos disponibles.

8. Evitar la impunidad de los actos dolosos sobre omisión a la asistencia familiar.

\subsection{Acciones prioritarias}

Las acciones propuestas deben ser evidentemente priorizadas en su atención. Sin embargo, encontramos que todas tienen igual importancia por lo que, como metodología de investigación, deben realizarse trabajos indispensables en busca de soluciones, ya sea planteando una secuencia o, en otros casos, en forma simultánea. Por ejemplo, como consecuencia del proceso de alimentos, se debe coordinar una fuente de trabajo inmediato con los municipios, empresas u otros sectores. Sobre este aspecto nos complace comentar sobre un caso real; en un gabinete consultivo de una corte superior de provincia, donde participaban distintos representantes, como el sub-prefecto de la provincia, el alcalde, el fiscal y la Policía Nacional del Perú, entre otras organizaciones, se realizó una visita de inspección a un juzgado de familia, en el que se llevaba a cabo una audiencia de un proceso de alimentos con asistencia de la demandante, su hijo de ocho años, el obligado y el juez. El obligado demandado manifestaba que no tenía trabajo estable, por lo que sus ingresos eran mínimos y de modo temporal, pero afirmaba que cuando mejore su situación no tendría ningún inconveniente de pasarle lo que el niño necesitaba, por una suma superior al 50\% de sus ingresos, por ejemplo el $80 \%$. En ese momento se hizo intervenir al alcalde que salía del gabinete y se le consultó si podría dar trabajo al demandado, quien aceptó y a partir de ese momento se sentó el acta, estipulando la cantidad requerida para el alimentista. Entonces, me pregunté si estábamos distorsionando el proceso. Considero que no. Toda vez que se ha tomado en cuenta el interés superior del niño $\mathrm{y}$, sobre todo que no hay afectación para ninguna de las partes, en consecuencia el proceso tiene valor. 
Otro caso, digno de señalar, para desformalizar el procedimiento sobre alimentos, fue aquel en el que el demandado afirmaba no tener ingresos para cubrir la pensión adeudada, cuando se estaba en la etapa de ejecución de la sentencia. El juez, en una feliz iniciativa, citó para ese mismo día a un deudor del padre e hizo efectiva la deuda pendiente, entregando el monto directamente al demandante de alimentos. Igual que el caso anterior, se preguntó el juez, que si el trámite sería el adecuado.

En otro caso muy singular, la madre demandante de los alimentos para su hijos, estaba de acuerdo con la suma que ofrecía el demandado, pero consultado con su abogado, sostuvo que no estaba conforme, por lo que apelaba la resolución. Se elevó el expediente al revisor, esta instancia superior, confirmó el monto señalado. La pregunta es jel tiempo y gasto invertido cómo se compensa?

\subsection{Propuesta de trabajo para desformalizar los procesos de alimentos}

Para este fin, teniendo en cuenta la prioridad del resultado en las acciones sobre alimentos la situación económica tanto de los reclamantes como de los demandados, sugerimos como propuesta de trabajo que los procesos de alimentos para menores (niños y adolescentes), cuya filiación se encuentra debidamente acreditada, puedan tener las siguientes características:

- Mantener la competencia territorial de los juzgados de paz o de paz letrado, a elección del reclamante.

- La demanda puede ser presentada por escrito o mediante acta, siendo optativa la intervención del abogado.

- Recibida y calificada la demanda, el juez debe adecuarla a derecho, y en la misma resolución se fijará la pensión provisional en base a la información racional proporcionada por la demandante. La pensión provisional no podrá ser inferior al sueldo mínimo legal, notificando al obligado para que señale bienes o garantice la pensión, bajo apercibimiento de embargo, señalando a la vez para la audiencia de esclarecimiento y conciliación en su caso, la que no se llevará a cabo sin pago total o parcial de la asignación provisional. En caso de incumplimiento, se expedirá copias para la denuncia por omisión alimentaria en la vía penal. 
- La carga de la prueba en la audiencia estará a cargo del demandado, para que acredite su real capacidad económica, y su conducta procesal servirá para expedir el fallo, otorgándole el derecho de defensa y la garantía del debido proceso.

- En la audiencia el juez debe tener la amplia libertad para establecer de manera efectiva y real la pensión, pudiendo realizar convenios con empresas públicas y privadas para crear fuentes de trabajo.

- En el campo penal, establecer sanciones drásticas en caso de mala fe. Si fuese el caso. en la pena privativa de la libertad establecer la obligación de trabajo interno o externo para el cumplimiento de la pensión.

\subsection{Sanciones por incumplimiento del pago de la pensión alimenticia}

Como hemos mencionado anteriormente, el problema central del incumplimiento de la obligación alimentaria radica en el hecho de que no se puede ejecutar el mandato judicial que dispone el pago de una pensión de alimentos, incumplimiento que en muchos casos es originado intencionalmente por el obligado.

A fin de evitar las omisiones de incumplimiento de obligación alimentaria de los obligados, y con el fin de proteger al niño o adolescente es que nuestro nuevo Código Penal ha establecido sanciones a fin de evitar dicha omisión, y de esa manera evitar que se siga eludiendo la obligación. Así lo establece en su artículo $149^{\circ}$, que señala: «El que omite cumplir con su obligación de prestar los alimentos que establece una resolución judicial será reprimido con pena privativa de la libertad no mayor de tres años, o con prestación de servicio comunitario de veinte a cincuentidos jornadas, sin perjuicio de cumplir el mandato judicial. Si el agente ha simulado otra obligación de alimentos en connivencia con otra persona o renuncia o abandona maliciosamente su trabajo la pena será no menor de tres años ni mayor de seis años en caso de muerte. Si resulta lesión grave o muerte y estas pudieron ser previstas la pena será no menor de dos ni mayor de cuatro años en caso de lesión grave, y no menor de tres ni mayor de seis años en caso de muerte"

Sin embargo, estas sanciones impuestas por nuestro ordenamiento sustantivo no son lo suficientemente drásticas para evitar que este problema que atenta contra Los niños y adolescentes disminuya o se evite. 


\section{6.- Ejecutorias sobre la obligación alimentaria.}

Sólo como muestra, presentamos algunas sumillas y transcripciones de ejecutorias sobre la forma como se considera los distintos aspectos tratados sobre la pensión alimentaria en el Perú.

\section{EJECUTORIA 34-A ${ }^{13}$}

Divorcio absoluto:

Abandono injustificado del hogar conyugal. conducta deshonrosa.

Procede amparar la pretensión de divorcio absoluto por abandono injustificado del hogar conyugal cuando éste se produjo con la intención manifiesta de sustraerse de las obligaciones conyugales.

Constituye conducta deshonrosa la realización de actos continuos y permanentes de parte de uno de los cónyuges que sobrepasen los límites del mutuo respeto y la consideración que debe existir entre ambos.

ALIMENTOS: Subsistencia de la obligación alimentaria a favor del cónyuge culpable.

El accionante queda liberado de la obligación alimenticia a favor de la demandada en vista de haber perdido ésta su derecho por ser la causante del divorcio y al no aducir que carece de medios de vida.

EXPEDIENTE N 612-97 - HUARAZ.

\section{EJECUTORIA 49-A}

\section{Alimentos}

Los alimentos deben regularse de acuerdo a la posibilidad de quien debe prestarlos y a las necesidades del alimentista, de manera que éste pueda atender sus obligaciones sin mayor apremio.

Causa Civil No 46-97

\section{EJECUTORIA N ${ }^{\circ} 36^{14}$}

\section{Alimentos}

Los alimentos se regulan en proporción a las necesidades de quien debe recibir y a las posibilidades de quien deba brindarlos y a las obligaciones a que se halle sujeto el deudor.

13 Serie de jurisprudencia Nro. 1: Academia de la Magistratura. Editorial Desa S.A.

14 Marianella Ledesma Narvaáez: Ejecutorias con aplicación del nuevo Código Procesal Civil Editorial Cultural Cuzco - 1995. Tomo 2. 
Teniendo la actora capacidad económica mayor que la del demandado, ésta puede atender su propia subsistencia.

EXPEDIENTE $\mathrm{N}^{\circ} 781-95$

EJECUTORIA $N^{\circ} 37$

Alimentos

La pensión de alimentos de una menor no puede ser materia de renuncia por la madre de ésta, toda vez que se trata de un derecho de la menor y no de la madre, quien legalmente, si puede renunciar por su propio derecho a los alimentos que le corresponde como cónyuge.

EXPEDIENTE $N^{\circ} 1419-95$

EJECUTORIAS $\mathrm{N}^{\circ} 38$

Alimentos

Si bien el demandado aduce estar desocupado, sin embargo tiene la obligación conjuntamente con la actora de velar por el sostenimiento del hogar según sus posibilidades.

EXPEDIENTE $\mathrm{N}^{\circ} 1114-95$

\section{EJECUTORIA N ${ }^{\circ} 39$}

\section{Alimentos}

No puede basarse el demandado, en no tener trabajo estable para proponer una suma que no está de acuerdo con las necesidades de su menor hijo.

EXPEDIENTE N $1074-95$

\section{EJECUTORIA $\mathrm{N}^{\circ} 40$}

Hijo alimentista

El hijo extramatrimonial sólo puede reclamar pensión alimenticia del que ha tenido relaciones sexuales con la madre durante la época de concepción.

EXPEDIENTE 1055-95

SEXTA SALA - AÑO: 95

\section{EJECUTORIA N ${ }^{\circ} 41$}

Hijo alimentista

El hijo extramatrimonial solo puede reclamar del que ha tenido relaciones con la madre durante la época de la concepción a una pensión alimenticia hasta la edad de 18 años. 
EXPEDIENTE N 703-95

SEXTA SALA - AÑO: 95

\section{TRANSCRIPCION DE ALGUNAS EJECUTORIAS}

\section{EJECUTORIA $N^{\circ} 38$}

\section{Alimentos}

Si bien el demandado aduce estar desocupado, sin embargo tiene la obligación conjuntamente con la actora de velar por el sostenimiento del hogar según sus posibilidades.

EXPEDIENTE $N^{\circ} 1114-95$

SEXTA SALA - AÑO: 95

Lima, nueve de Junio de mil novecientos noventicinco.- VISTOS; interviniendo como Vocal ponente el Señor Seminario Valle; por sus fundamentos; de conformidad con la opinión de la Señora Fiscal Superior de fojas setentitrés; y CONSIDERANDO: además, que según el acta de audiencia única de fojas treintisiete y treintiocho, las partes llegaron a la conciliación que sea la madre quien siga teniendo en su poder a sus tres menores hijos, lo que es aprobado por el juzgado con respecto a la tenencia a favor de la demandante; que prosiguiendo el trámite del proceso en el extremo de los alimentos, se aprecia que si bien no está plenamente demostrado que el demandado tenga trabajo estable con sueldo fijo, aduciendo más bien estar desocupado, sin embargo tiene obligación conjuntamente con la actora al sostenimiento del hogar según sus respectivas posibilidades; que la suma fijada por la juez es equitativa y justa, en vista del número de menores alimentistas; CONFIRMARON la sentencia apelada de fojas cuarentitrés a cuarenticinco, que declara fundada en parte la demanda interpuesta por doña Bertha Irma Cisneros Núñez contra don Víctor Benjamín Gonzáles Sánchez sobre alimentos; en consecuencia ordena: que el obligado debe atender al sostenimiento de sus hijos Liubica Miluska Massiel, Hans Fischer Winston y Mirella Yesabella Gonzáles Cisneros de tres, dos y un año de edad respectivamente, así como para la esposa con la suma de doscientos cincuenta nuevos soles, correspondiéndole a cada hijo setenta nuevos soles, y a la madre la suma de treinta nuevos soles, en forma adelantada; con lo demás que contiene; y los devolvieron.- Señores FERREYROS PAREDES / SEMINARIO VALLE / MIRANDA CANALES. 


\section{EJECUTORIA N ${ }^{\circ} 39$}

Alimentos

No puede basarse el demandado, en no tener trabajo estable para proponer una suma que no está de acuerdo con las necesidades de su menor hijo.

EXPEDIENTE 1074-95

SEXTA SALA - AÑO: 95

Lima, diez de mayo de mil novecientos noventicinco.- VISTOS; interviniendo como Vocal ponente el Señor Seminario Valle; por sus fundamentos; y CONSIDERANDO: además, que es deber de los padres acudir con alimentos, vestido, habitación y asistencia médica, según la situación y posibilidades de la familia, correspondiéndole a ambos padres; que, el demandado no puede basarse en no tener trabajo estable para proponer una suma que no está de acuerdo con las necesidades de su menor hijo matrimonial, quien tiene nueve años de edad; por lo que estando al artículo cuatrocientos ochentidós del Código Civil; CONFIRMARON la sentencia apelada de fojas treinta a treintidós, su fecha veintidós de Diciembre de mil novecientos noventicuatro, en la parte que ordena al demandado don Juan Agapito Gonzáles Torres acudir a la actora y a su menor hijo con una pensión alimenticia mensual y adelantada; REVOCARON la propia resolución en el extremo que fija dicha pensión alimenticia, la misma que fijaron en doscientos cincuenta nuevos soles, correspondiéndole doscientos nuevos soles al menor alimentista y cincuenta nuevos soles a la esposa; con lo demás que contiene; y los devolvieorn.- Señores FERREYROS PAREDES / SEMINARIO VALLE / VALCARCEL SALDAÑA.

\section{EJECUTORIA N ${ }^{\circ} 40$}

Hijo alimentista

El hijo extramatrimonial sólo puede reclamar pensión alimenticia del que ha tenido relaciones sexuales con la madre durante la época de concepción.

EXPEDIENTE N 1055 - 95

SEXTA SALA - AÑO 95

Lima, veintiocho de Junio de mil novecientos noventicinco.- VISTOS; interviniendo como Vocal ponente el Señor Ferreyra Paredes; con lo expuesto por la Fiscalía Superior en su dictamen de fojas dos- 
cientos seis; y, CONSIDERANDO: que la partida de nacimiento de fojas uno demuestra que la demanda de fojas tres se refiere a la pensión de un hijo alimentista; que por consiguiente la acción se sitúa en lo dispuesto por el artículo cuatrocientos quince del Código Civil, en cuya virtud el hijo extramatrimonial sólo puede reclamar pensión alimenticia del que ha tenido relaciones sexuales con la madre durante la época de la concepción; que en ese sentido no se ha acreditado en autos que el emplazado haya tenido tales relaciones con la actora durante dicha época; que debe tenerse en cuenta que la constancia de fojas ciento catorce, que no está autenticada ni reconocida, que ha sido remitida por el administrador del hostal "Hong Kong" se refiere al día dos de febrero de mil novecientos noventitrés, en la que aparecen registrados los coaccionantes en la mencionada fecha en el citado hostal, hecho que resulta irrelevante para establecer la época de la concepción de la menor Lisset Estefanía Moreno Vilcapoma, nacida el nueve de Diciembre de mil novecientos noventa, después de dos años, lo que no prueba que las relaciones sexuales hayan sido en la época de la concepción; REVOCARON la resolución apelada de fojas ciento setentiocho, su fecha dos de Marzo último, que declara fundada en parte la demanda de alimentos de fojas tres interpuesta por Antonia Beatriz Vilcapoma Vilcapoma una pensión alimenticia; MODIFICANDOLA declararon infundada dicha demanda y lo demás que contiene; y los devolvieron.- Señores FERREYROS PAREDES / SEMINARIO VALLE / PALOMINO THOMPSON. 